Mavi Atlas, 5(1)/2017: 1-8.

Araştırma Makalesi | Research Article

Makale Geliş | Received: 19.03.2017

Makale Kabul | Accepted: 27.03.2017

Doi: $10.18795 /$ gumusmaviatlas.304287

Oğuz HAŞLAKOĞLU

Doç. Dr. | Assoc. Prof. Dr. İstanbul Teknik Üniversitesi, Mimarlık Fakültesi, Mimarlık Bölümü, İstanbul-Türkiye İstanbul Technical University, Faculty of Architecture, Department of Architecture, İstanbul-Turkey haslakoglu@itu.edu.tr

\title{
Sanatsal Değer ve Ekonomik Değer Arasındaki İlişkiye Etik Açıdan Bakış
}

$\ddot{O} z$

Bu makalede sanatsal ve ekonomik değer ilişkisi özgürlük ve özerklik bağlamında etik boyutuyla ele alınmaya çalışılmıştır. Sanatta özgürlüğü, insanın evrensel anlamda "hür oluş" kabulü üzerinden, gerek yapıtın yaratıcı özgünlük koşulu gerekse toplumsal sorumluk bağlamını tanımlamak için kullanan yaklaşım, özerkliği de sanatın içinde bulunduğu sermaye birikimini esas alan üretim koşulları içinde özellikle "kültür endüstrisi" kavramıyla gelinen noktada tarihsel perspektifi de dikkate alarak eleştirel önceliğe vurgu yapan yanıyla ortaya koymaktadır.

Anahtar Kelimeler: Sanat, Değer, Etik, Özerklik, Sanatın Toplumsal Sorumluluğu, Ekonomik Değer.

\section{The Relationship between Artistic and Economic Values in View of Ethics}

\begin{abstract}
The essay focuses on the ethical dimension concerning the relationship of artistic and economic values within the context of freedom and autonomy. The approach takes its starting point from the acknowledgement of the human being as a free agent and applies it as the condition of any art work to be genuinely original as well as using it as a criterion against mere caprice within the context of social responsibility. In the same way, by shortly presenting the historical perspective on the matter, autonomy in art is emphasized in its critical aspect in so far the artist is living within the mode of production that is determined by "cultural industry".
\end{abstract}

Keywords: Art, Value, Ethics, Autonomy, Social Responsibility of Art, Economical Value. 
Sanatsal değer ve ekonomik değer, her birinin dayandığı kategorik anlamda farklı değer dünyaları bakımından hem karşılıklı birbirini dışlayan hem de zorunlu olarak içeren 'ne senle ne de sensiz' türü çelişik bir ilişki tarzına sahip. Bir yandan sanatın değeri hiçbir zaman ekonomik değere indirgenemez çünkü sanat -bu ne kadar gerçekçi olmayan bir ifade gibi görünürse görünsün- satılmak için yapılmaz, diğer yandan da eskilerin deyimiyle "marifet iltifata tâbidir, satın alınmayan meta zayidir", çünkü sonuç olarak geliri olmadan sanatçının maddi hayatını yeniden üretebilmesi mümkün değildir. O halde iki değer arasında nasıl bir ilişkiden söz edilebilir? Bu soru aslında ister istemez sanatın içinde değer bulduğu toplumu ve onun maddi hayatının yeniden üretilmesi koşullarını gündeme getirmeyi gerektirir. Bu da ekonomik değerin günümüzde tümüyle kapitalist bir ekonomi içinde belirlendiğini hatırlamamızı sağlar. Kapitalizm, sermaye birikimi esaslı bir ekonomik düzen olduğuna göre de sanatı Adorno'nun deyimiyle "kültür endüstrisi” bağlamında esasen "metalaştırma" dışında kâr amaçlı bir ekonomik değer haline getirmesi mümkün değildir. İşte tam burada kapitalist sistemin tipik tezahürü olan emeğine yabancılaşan emekçinin kaderiyle sanatçınınkinin kesiştiği görülür. Buradaki yabancılaşma bağlamına bakıldığında sanki sanatçı kendi atölyesinde ürettiği bir ürünü satıyor olduğu için tipik bir emekçi gibi ekonomik sömürüye doğrudan maruz değil gibidir. Üstelik esasen hukuki bağlamda tanımlandığı şekliyle serebral bir faaliyet olarak sanatın, giderek daha fazla biçimde fiziksel bir otomasyon düzeyine indirgenmeye çalışılan genel anlamdaki 'kol emeğine' nazaran farklı bir kategoride olduğu da açık. Ne var ki emeğin niteliğindeki fark ne olursa olsun bir sanatçının da hayatını yeniden üretebilmesi için, içinde bulunduğu ekonomik sisteme tıpkı diğer tüm emekçiler gibi aynı koşullarda tâbi olduğu görülür. Kapitalist sistemin en ürkütücü yanlarından biri, bütün bir toplumsal hayatı, sermayenin mutlakıyetine dayalı ekonomik düzenin ruhuna uygun biçimde kuşatıcı bir mekanizma haline getirmesidir. $\mathrm{Bu}$ anlamda makineleşme bir bilim kurgu metaforu olmaktan öte ekonomik ilişkiler mekanizmasına tâbi olmanın getirdiği belirleyici ve zorunlu bir yaşantı olarak karşımıza çıkar. Zaten bu durumun kavramsallaştırılması olarak yabancılaşma, Marx'ın ortaya koyduğu esasta; nesnel ekonomik ilişkilere indirgenerek maskelenmek suretiyle iptal edilen, insanı bir 'sosyal varlık' olarak özünde (Wesen) 
tanımlayan toplumsal bağlamdır. Başka bir deyişle, her türden emeğe yabancılaşma, metalaştırılma yoluyla, her şeyden önce insan doğasının 'olmazsa olmaz' koşulu olan toplumsallaşmayı ortadan kaldırır. O halde metalaştırma yoluyla toplumsal ilişkinin baskılanmasıyla/maskelenmesiyle oluşan yabancılaşmanın, sanatın kendi içindeki değerine toplumsal bağlamdaki etkisi nedir? $\mathrm{Bu}$ sorunun yanıtı, sanatsal değerle ekonomik değer arasındaki ilişkinin özgürlük ve özerklik bağlamında anlaşılması kaydıyla etik boyutuna 1şık tutar.

Sanatın toplum için mi yoksa kendisi için mi olduğuna dair esasen hiç bir anlam taşımayan derinlikten yoksun sorunsalı bir kenara bırakırsak, türü ne olursa olsun sanatsal hiç bir faaliyetin, tümüyle indirgenmez olduğu toplumsal bağlamdan aynı zamanda tümüyle de soyutlanamayacağı görülür. Böyle olunca da sanat ve toplum ilişkilerinin ve dahası sanatın -toplumsal etkisine bağlı olarak- bizatihi işlevinin ne olabileceği sorusu ortaya çıkar. Bu da sanatın işlevini tanımlayan biçimsel bir tecrübeyi yaşantı karşılığı olarak tanımlar. Yaşantının beğeni esasında tecrübe edilmesine hizmet eden 'estetik kültür' örneğin tam olarak böyle bir bağlamın eseridir çünkü bir şekilde güzellik bir değer olarak sosyal ve kültürel davranış biçimlerinde belirleyici bir role sahiptir. Oysa asıl sorun tam da güzelliğin bir değer olarak indirgendiği 'estetik bağlam' içinde tanımlanmasında yatar çünkü sanatta yapan-bakan ilişkisi ne yazık ki Kant’tan beri içine hapsolduğu 'biçimci' (formalist) köklerinin izini taşır. $\mathrm{Bu}$ tespitin anlamı şudur: sanat estetik bağlamda güzelliğin tanımı ve tecrübesinde yalnızca 'biçim' esasında oluşan ve "estetik" sözcüğünün de geldiği aisthēsis (duyusal deneyim, hissetme) esasında bir beğeniye indirgenerek tanımlandığı ve belirlendiği sürece, sanatın toplumsal etki ve işlevinin, niteliği ne olursa olsun, Adorno'nun deyimiyle "kültür endüstrisi”ne hizmet etmesi kaçınılmazdır. Oysa sanatın en temel niteliği; sanatçının yaratıcı fiiline hükmeden hürleşme saikinin -'konu'dan farklı olarak- içerik itibariyle mimetik bağlamda büründüğü malzeme ve biçimi benzersiz kılan özelliğinde ortaya çıkan bir tür “artık değer (surplus value)” olarak 'özerklik' (autonomy) bağlamıdır. Böylece sanat, seçkinci bir anlayışın kaprisinden ayırt edilmesi gereken bu sahih anlamında özerkliğini içinde yaşadığı toplumun Adorno'nun ifadesiyle bir anti- 
tezi olarak konumlayarak onu çelişkilerinde ortaya koyan eleştirisini üstlenebilir. $\mathrm{Bu}$ anlamda sanat, her şeyden önce işe "dünya hâli" olarak önüne konulan "böyle gelmiş böyle gider" kabulünün reddiyle başlar ve bunun nedeni hürleşme saikinin sanatın, özellikle de modern sanatın altta yatan asıl pathos'unu oluşturmasıdır. Bu açıdan bakıldığında sanat gerçekliğin bir taklidi ve/veya temsilini üstlenmez; bizzat düşlemek sûretiyle zaten değişime tâbi gerçekliğin her an yeniden inşa edilebileceğini ve böylece de tıpkı bir sanat eseri yaratılabileceğini gösterir.

Tarihsel perspektiften bakıldığında, özerkliğin, Kant estetiğinde güzelliğin, 'hayal gücü (Einbildungskraft)' ve 'idrak' (Verstand)' yetilerinin 'serbest oyunu' ve 'uyumu' içinde (Kant 1952: 60) Kant'ın verdiği isimle 'estetik idea' olarak (1952: 210) 'tecelli ettiği’ (Darstellung) 'darp izinde’ (Hypotyposis) 'sembolik' bağlamda ortaya çıktığ1 (1952: 221-222) hatırlanırsa, güzellik tecrübesine ancak kendisini belirleyen gerçeklikten -oyunun hürleştiren ve uyumun çelişkiyi gideren özellikleri sayesindeazade oluşuyla ulaşılabildiği de görülür. Buna karşın Hegel estetiğinde özerklik ise bizatihi yaşamın kendisi olan çelişkiyi 'değilleyerek içeren' (Aufhebung) olumlu bütünlüğü (Totalität) içindeki hakikat olarak tanımlanan idea'nın bir öz oluşunda mahiyetini belirleyen görünme koşuluna 'tam uygunluk' olarak ideal'i gerçekleştirmek için koyulduğu 'biçim' arayışıdır (Bkz. Hegel 1994: 73-74, 111, 114). Hegel düşüncesinde bu 'ideal' biçim bulunduğunda hakikat sanat yapıtında kendisini ne bilim ne de tarihte olmadığ Hegel estetiğinin bu hakikat ve sanat bağlamını "hakikat esası (Wahrheitsgehalt)" (Bkz. Adorno 2012: 88, 128-129, 341) adıyla kendi estetiğinin merkezi kavramı haline getiren Adorno ise geliştirdiği 'olumsuz diyalektik' (Adorno 2014: 139-153) yoluyla, 'özdeş olmayan' (Nicht-Identisch) kavramıyla tanımladığı bir tür yarım bırakılmış çelişki içinde asılı diyalektik anlayışıyla Hegel'den ayrılır ve özerkliğin her zaman sanat yapıtının metalaştırılmasıyla diyalektik bir çelişki içinde anlaşılması gerektiğini söyler. Böylece Adorno’ya göre özerklik ve metalaştırma arasındaki bu uzlaşmaz çelişki, modern sanatın, izleyicisinden önce kendi içinde kendisine yabancılaşmasına neden olur. 
Yukarıda kısaca özetlenen görüşlerin tümünün klasik düşüncenin bir özelliği olarak sistem felsefesi geleneği içinde yer alması (Adorno da kendi düşüncesi içinde olmasa da esasen bağlandığı Marxists ideoloji anlamında buna tâbidir) sanatı bir fiil olarak gerçekleştiği yaratıcılık esasını belirleyen kendi nesnel koşullarında anlamayı hem ertelemiş hem de zorlaştırmıştır. Oysa sanatın her şeyden önce yaratıcı fiilinde hür olması gereği açıktır, aksi takdirde sanatsal yaratının 'olmazsa olmaz' koşulu olan özgünlükten, hem insan türünün 'iz bırakmaya' dayalı sui generis ifade tarzı hem de türün kendi içinde söz konusu bireysel bağlamında söz edilebilmesine zaten imkân yoktur. Bu durum çerçevesinde ortaya konulması gereken kendi içinde sorunlu sanat ve kültür ayrımı bir yana, sanatı meydana gelme esasında tanımlayan bu 'hürleşme' ilkesinin aynı zamanda sanatsal her türlü faaliyetin, kendi evrensel tanımı içerisinde esasen insanın 'hür oluşu' kabulüne dayandığını gösterir. Böylece de etik ve estetik kaçınılmaz biçimde örtüşmek zorunda kalırlar çünkü tümüyle insani bağlamda bir değer etkinliği olarak sanat onun toplumsal bir varlık oluşundan söküp alınamaz ve hürleşme tam da basit bir kapris olmaktan onun çıkaracak olan özerklik ve metalaşma arasındaki diyalektik bağlamını ancak toplumsal sorumluluk üzerinden kazanır.

Diğer yandan bir sanat yapıtının her şeyden önce fiil esasında anlaşılması kaydıyla ontolojik anlamı bakımından, bakanı, karşı taraftan 'seyreyleyen' değil, tıpk1 sanatçı gibi bizatihi 'eyleyen' olarak konumlaması gerektiği görülür çünkü sanat yapıtının tecrübesinde yapan/bakan ayrımının diyalektiğine hükmeden mimetik ilke her şeyden önce seyircinin kendisini sanatçının yerine koymasını gerektirir. Ne var ki burada 'kendini yerine koyma' basit anlamda duygusal bir empati bağlamını tanımlamaz; 'yapan'ın en başından itibaren aslında aynı zamanda 'bakan' oluşunun sanatsal anlamdaki ontolojik esasta zorunlu bir gereğine işaret eder. 'Yapan', kendi fiili itibariyle aynı zamanda da 'bakan' olduğu içindir ki sanat yapıtı öznenin kendisini hürleşme yoluyla başkası olarak kurmasının cisimleşmiş bir manifestosudur. $\mathrm{Bu}$ anlamında hürleşme Rimbaud'nun ifadesiyle ‘ben'in 'her zaman' bir başkası olmasıdır'

\footnotetext{
${ }^{1}$ Rimbaud'nun (1854-1891), Türkçede genelde "Ben bir başkasıdır" şeklinde karşılanan Je est un autre ifadesi, şairin 13 Mayıs 1871 tarihli Georges Izambard'a ve 15 May1s 1871 tarihli Paul Demeny’ye gönderdiği mektuplarda karşımıza çıkar (Mektupların Türkçesi için, bkz. Rimbaud 2008: 63-80).
} 
çünkü kendisini, özdeşleşme olmaksızın (bu zaten hem mimetik hem de ontolojik anlamda imkânsızdır) ancak başkasıyla tamamlayarak tanımlayabilir. Esasen insanın bir sosyal (socio; ortak) varlık oluşunu tanımlayan özü (Wesen) de buradan gelir; insani anlamında hakikat ancak başkasıyla -benzeşmeksizin- 'bir arada' mümkündür. Bu sebepledir ki kendisini aşan bir 'yapay nesne' (artefact) olarak 'sanat yapıtı' bakan konumunu adet olarak çoğaltmaz; bilincin en başından itibaren bir başkası üzerinden kendisini tanımladığı ortak toplumsal varlığın farkındalığında, seyircisini içine savrulduğu yanılsamalı özne konumundan çekip çıkararak içinde bulunduğu dünyadan sorumlu olduğu gerçeğiyle yüzleştirir.

$\mathrm{Bu}$ ilginç durum, aslında modern sanatın da temel ilkesini oluşturur çünkü modern sanat Hegel'in etkileyici tespitiyle; 'biçimin düşünce lehine aşılması' üzerine kuruludur. Bu şekilde düşüncenin sanatın yaratıcı ilkesi haline gelmesi, sanatçıyı doğayı görünüş olarak taklit etme zorunluluğundan kurtarmış ve onu kendi içinde başlı başına özerk ve bağımsız bir doğa haline getirmiştir. Bunun anlamı: 'yapma'nın modern sanat için Descartes'ın sezgisel yoldan düşünceden varlığa ulaşan cogito ergo sum'una nazire yaparcasına artık bir ‘olma'ya dönüşmesidir. Picasso'nun “sanat yapılan bir şey değildir çünkü sanatta esas olan yapmak değil olmaktır; örneğin Cézanne eğer Jacques-Emile Blanche gibi 'düşünmüş ve yaşamış olsaydı' beni hiç ilgilendirmezdi çünkü bizi Cézanne'a bağlayan onun kaygısıdır, elmalarının güzelliği değil” (akt. Ashton 2001: 69) dediğinde kastettiği tam olarak budur. Ve düşünce her zaman ya hürdür ya da zaten düşünce değildir çünkü düşünce her zaman tek başına ne olumlu ne olumsuz anlamda belirleyici yargıdır; o daha ziyade olumlu ve olumsuz yargının durmaksızın birbirine devrettiği sınırda savrulmaksızın duran, felsefenin başlangıcına egemen ruh hali (pathos) olan hayretin (thaumazein) dile gelişi olarak bizatihi sorudur.

Burada gelinen nokta, sanatın toplumsal etki ve işlevini de gözler önüne serer: eğer bir sanat yapıtı 'hür olma' ilkesinden hareket eden bir sanat düşüncesini esas alamıyorsa ne kadar provokatif bir biçim/içerik bağlamına sahip olsa da beğeni yargılarını muhatap alan biçimi üzerinden kaçınılmaz bir biçimde metalaştırıldığ ekonomik sisteminin bir parçası haline gelerek sadece bir tüketim nesnesine dönüşür. 
Bunun anlamı da açıktır; bir sanat yapıtı sanat oluşunu da belirleyecek şekilde ya insan hakikatine işaret edişinin bir gereği olarak hürleşmeden yanadır ya da bir sanat yapıtı değildir; başka bir alternatif yoktur. Aynı nedenle de bir sanatçının başına gelebilecek en talihsiz olay, kendisine sunulan altın kafeste şakıyan bir bülbül olmaya razı olmasıdır çünkü kariyeri artık tümüyle yaparak tüketmeden ibaret, şöhretin çarmıhına gerilmiş aslında bir tükenme trajikomedisidir. Dolayısıyla da esasen etik bağlam, sanatta sanatçının ne yaparsa ahlaklı olabileceği türünden bir ön kabul içeren ahlakçı anlayış üzerine kurulamaz. Asıl sorun, sanatçının bir insan olarak kendi hakikati ve hür olmayla kurduğu ilişkidir ve bunu hayatını yeniden üretebilmesi için gerekli zorunlu bir koşuldan, tümüyle 'kendinden menkul' bir ekonomik 'özgürleşmeye' dönüştüren yolda elden çıkarıyorsa bu Faustvari alışverişte aslında satıyor olduğu kendi ruhudur. 
Oğuz HAŞLAKOĞLU, “Sanatsal Değer ve Ekonomik Değer Arasındaki İlişkiye Etik Açıdan Bakış", Mavi Atlas, 5(1)/2017: 1-8.

\section{KAYNAKÇA}

ADORNO, Theodor W. (2001). Negatif Diyalektik, çev. Şeyda Öztürk, İstanbul: Metis Yayınları.

ADORNO, Theodor W. (2012). Aesthetic Theory, trans. Robert Hullot-Kentor, Continuum.

ASHTON, Dore (2001). Picasso Konuşuyor, çev. Mehmet Y1lmaz ve Nahide Karaağaç, Ankara: Ütopya Yayınevi.

HEGEL, G. W. F. (1994). Estetik: Güzel Sanat Üzerine Dersler (cilt 1), Taylan Altuğ ve Hakkı Hünler, İstanbul: Payel Yayınevi.

KANT, Immanuel (1952). The Critique of Judgement, trans. James Creed Meredith, Oxford University Press.

RIMBAUD, Arthur (2008). Ben Bir Başkasıdır (Bütün Düzyazı Şiirleri), çev. Özdemir İnce, İstanbul: Kırmızı Yayınları. 